\title{
Does One Bad Apple(Juice) Spoil the Bunch? Implicit Attitudes Toward One Product Transfer to Other Products by the Same Brand
}

\author{
Kate A. Ratliff, Bregje A. P. Swinkels, and Kimberly Klerx \\ Tilburg University \\ Brian A. Nosek \\ University of Virginia
}

\begin{abstract}
If people like a product, they will automatically like another product from the same brand even if they do not know anything about it (demonstrated in Study 1). In one sense, this may be a reasonable inference-brands that have one good product may be likely to have other good products. But what if people learn that the second product is actually not good? Explicitly, people act as expected-the second product is disliked based on its negative features. Implicitly, however, people's positive attitude toward the first product still influences their liking of the second (Study 2). This attitude transfer effect (Ranganath \& Nosek, 2008) shows that people are able to avoid using the qualities of one product to judge another explicitly. But, implicitly, once an attitude is formed toward a brand's product, other products by that brand will inherit some of the original evaluation regardless of their unique qualities. (C) 2012 Wiley Periodicals, Inc.
\end{abstract}

Imagine you are standing in a convenience store trying to decide between two brands of orange juice. You have never tried either one, though one of the brands makes an apple juice that you like. Does knowing that the brand makes good apple juice lead you to think more positively about their orange juice? On one hand, you might reason that a company that is good at making one product is probably good at making other products. On the other hand, knowing that a company makes one good product might not actually tell you anything at all about their other products. In the present research, the role of attitude transfer-the formation of attitudes toward a novel stimulus based on its associations with other valenced stimuli (Ranganath \& Nosek, 2008)—in the formation of implicit and explicit attitudes toward consumer products is explored.

\section{ATTITUDES AND ASSOCIATIVE LEARNING}

Although not always explicitly stated, a philosophy of associationism forms the bedrock of attitude formation research. Though there are many conceptions of associationism, the simplest form is that all knowl- edge is based on connections between ideas (Shanks, 1995). There is widespread agreement among learning theorists and social psychologists that attitudes may be acquired through associative learning (Cacioppo, Marshall-Goodell, Tassinary, \& Petty, 1992; Eagley \& Chaiken, 1993; Olson \& Fazio, 2002; Walther, Nagengast, \& Traselli, 2005; see De Houwer, 2009 for an alternative). Associationism also provides an explanation for the fact that most knowledge is more complex than a simple summary of direct experience. For example, one might be able to speculate about the quality of a product (e.g., orange juice) without having actually used it, based on evaluations of other products made by the same brand (e.g., apple juice).

The importance of associationism is evident in a popular definition of attitude as an "association between a concept and an evaluation-positive or negative, favorable or unfavorable, or desirable or undesirable" (Fazio, 1986, p. 214). Attitudes provide assessments that assist in decisions about how to interact with the world and provide useful orienting information and help to guide judgment and behavior. Although historical definitions of attitudes ignore the relevance of consciousness (Allport, 1935; Fazio, 1986; Sarnoff, 1960; Thurstone, 1931), modern dual-process models suggest 
that qualitatively distinct processes are involved in social evaluation (Gawronski \& Bodenhausen, 2006; Greenwald \& Banaji, 1995; Wilson, Lindsey, \& Schooler, 2000).

Explicit attitudes are those attitudes that result from introspection and that are consciously experienced as one's own. In contrast, a popular definition of implicit attitudes characterizes them as "introspectively unidentified or inaccurately identified traces of past experience that mediate favorable or unfavorable feeling, thought, or action toward social objects" (Greenwald \& Banaji, p. 5). Evidence suggests that implicit and explicit attitude assessments reveal distinct but related constructs (Nosek, 2005; Nosek \& Smyth, 2007; Ranganath, Smith, \& Nosek, 2008), and have distinct predictive validity (Greenwald, Poehlman, Uhlmann, \& Banaji, 2009). For example, a person might regularly be exposed to negative ideas about old people and aging. Consciously, this person might disagree with the negative ideas and maintain a positive explicit attitude toward the elderly and aging. Implicitly, however, this negative information may be stored as associations between negativity and old age (Nosek et al., 2007).

In the realm of consumer behavior, measures of implicit attitudes, such as the Implicit Association Test (IAT) (Greenwald, McGhee, \& Schwartz, 1998) are particularly useful in cases where consumers' behaviors or opinions are influenced by sources that they are unwilling or unable to identify (Brunel, Tietje, \& Greenwald, 2004). Further, the IAT can add predictive validity beyond that of self-report. Maison, Greenwald, and Brown (2004) found that the IAT can discriminate participants' implicit brand preferences (Coke vs. Pepsi) and predict product usage and brand recognition.

Theories of attitude formation suggest that both implicit and explicit attitudes are influenced by associations, though in different ways. Gawronski and Bodenhausen (2006) propose that the difference between implicit and explicit attitudes can be understood by the differential influence of associative and propositional processes (see also Sloman, 1996; Smith \& DeCoster, 2000; Strack \& Deutsch, 2004). According to their APE model, implicit attitudes reflect valenced (i.e., positive or negative) associations that are activated automatically upon encountering a relevant stimulus. So "association" in this case refers to the extent that the activation of one concept in memory (e.g., Brand X Orange Juice) increases the accessibility of another, evaluative concept (e.g., refreshing). This activation process does not require an intention to evaluate because associations do not inherently possess a truthvalue; that is, people can have associations in their minds that they would judge to be false if given the opportunity to evaluate them.

Explicit attitudes, according to the APE model, derive from deliberative processes that operate on existing associations. Explicit attitudes can be influenced by associative learning in that propositional reasoning enables the validation or rejection of associations. In this way, associations can influence explicit atti- tudes (Gawronski \& Bodenhausen, 2006; Gilbert, 1991; Ranganath \& Nosek, 2008; Smith, Ratliff, \& Nosek, 2012; Strack, 1992). In summary, recent work showing the distinctiveness of implicit (associative) and explicit (deliberative) evaluations provides evidence that people can possess multiple evaluations of a single target and that different types of experiences might influence evaluation in different ways.

\section{ATTITUDE FORMATION THROUGH ATTITUDE TRANSFER AND BRAND EXTENSION}

Attitude transfer can be defined as the formation of attitudes toward a novel stimulus based on its associations with other valenced stimuli (Ranganath \& Nosek, 2008; Ratliff \& Nosek, 2011). In a study of differences in implicit and explicit attitude generalization, Ranganath and Nosek found that associative links (e.g., shared group membership) are sufficient for implicit attitude transfer, but that deliberative logic (e.g., recognition individual group members are not necessarily the same) can reduce explicit attitude transfer. After exposure to positive and negative behaviors performed by an individual from each of two different groups, participants were introduced briefly to new individuals from the groups. Implicit evaluations of the original individuals readily generalized to the new individuals; explicitly, participants resisted such generalization.

Attitude transfer in the realm of consumer behavior is most related to research on brand extension, a marketing tool in which a current brand name is used to enter a different product class (Morein, 1975). Brand extensions are based on the premise that consumers hold positive attitudes toward the parent brand and that these positive attitudes can be transferred to the extension of the brand (Kapoor \& Heslop, 2009). The positional advantage of a strong brand name can substantially reduce the risk of introducing a new product by providing consumers the familiarity of an established brand (Aaker \& Keller, 1990).

Aaker and Keller (1990) showed that negative (explicit) evaluations of a given brand can be neutralized by elaborating on the attributes of the brand extension (the new product). However, the reviewed research on implicit attitude formation suggests that the original negative association with the brand might persist despite the (new) positive information (Ranganath \& Nosek, 2008). For example, Gregg, Seibt, and Banaji (2006) demonstrated that, once formed, implicit and explicit attitudes are differentially sensitive to counterattitudinal information. After an attitude induction procedure in which a preference was formed for one fictitious social group over another, participants were told that, due to a computer error, the information about the groups was switched and that the information they read about one group was actually true of the other. While explicit attitudes were easily reversed, implicit 
attitudes continued to favor the group that they had originally read positive information about.

Rydell, McConnell, Mackie, and Strain (2006) presented participants with positive and negative behaviors and asked them to judge whether those behaviors were characteristic or uncharacteristic of a target person, Bob. Positive implicit attitudes toward Bob were formed when participants were rewarded for responding that positive behaviors were characteristic of Bob; negative implicit attitudes toward Bob were formed when participants were rewarded for responding that negative behaviors were characteristic of Bob. Participants were then given information about Bob that was opposite in valence to what they had previously learned. Explicit attitudes changed quickly in response to relatively small amounts of counter-attitudinal information, reflecting deliberate, rule-based reasoning. On the other hand, implicit attitudes changed more slowly, and in a linear fashion, in the face of counter-attitudinal information (see also Rydell, McConnell, Strain, Claypool, \& Hugenburg, 2007; Wilson et al., 2000).

Taken together, past research supports the hypothesis that implicit attitudes toward one product will generalize to a new product made by the same brand, even when information about the new product is opposite in valence to the original information. Study 1 tested the attitude transfer effect within the consumer behavior realm, by forming implicit and explicit attitudes toward one product and showing that they transfer to a second product made by the same brand. Mediation analysis showed that implicit attitude transfer mediated the effect of product information on explicit attitude transfer, suggesting that the effect occurs automatically. Experiment 2 extended this demonstration by showing that the formed implicit and explicit attitudes toward one product influence evaluations of the second product even when the participant receives specific information about the second product that is opposite in valence.

\section{STUDY 1}

Participants read about fictitious body lotions that induced a clear preference for one brand over the other. In one condition, the Vode Body Lotion had positive features and the Veani Body Lotion had negative features; in the other condition, this was reversed. Previous research has shown that implicit and explicit attitudes form in line with valenced information presented about novel stimuli (Ranganath \& Nosek, 2008; Ratliff \& Nosek, 2010). Participants then read brief introductions to two new products, deodorants, made by the same brands. The information about the deodorants was minimal and evaluatively equal, ensuring that any differences in evaluations of the two new products could be attributed only to pre-existing attitudes toward the Vode and Veani Body Lotions that were the targets of the original attitude induction. We then measured participants' self-reported and implicit attitudes toward Vode and Veani Deodorants (the new products) using the IAT (Greenwald et al., 1998). The IAT is a reliable and valid measure of implicit consumer preferences (Brunel et al., 2004; Gibson, 2008; Greenwald et al., 2009; Karpinski, Steinman, \& Hilton, 2005; Maison et al., 2004). See Figure 1 for an overview of the Study 1 procedure.

\section{METHOD}

\section{Participants}

Participants were volunteers at the Project Implicit research Web site (http://implicit.harvard.edu) who were randomly assigned to this study from the available pool of dozens of studies. Two hundred seventy-one people completed the study materials ( $65 \%$ women, $M_{\text {age }}$ $=26.8$ years). For more information about the virtual laboratory, see Nosek (2005).

\section{Materials}

Attitude Induction Procedure. Participants viewed a series of 14 sentences describing attributes of Vode and Veani body lotions. In the Vode Body Lotion Positive condition, seven sentences described positive qualities of Vode Body Lotion and seven sentences described negative qualities of Veani Body Lotion; in the Vode Body Lotion Negative condition, seven sentences described negative qualities of Vode Body Lotion and seven sentences described positive qualities of Veani Body Lotion. The information about one lotion was all positive and the information about the other lotion was all negative in order to ensure a clear preference for one lotion over the other. Each sentence was paired with a picture of the lotion (see Appendix for sentences). The 14 attribute-picture pairs appeared on a computer screen one at a time for three seconds each. The induction procedure took approximately one minute.

Introduction to New Products. Participants were given information about two new products (deodorant) made by the same companies (Vode and Veani) that produce the body lotions that they had learned about previously. The information about the new products was:

\footnotetext{
Vode deodorant is a fresh smelling deodorant that leaves your skin soft. But, when Vode deodorant gets old it sometimes loses its fresh scent.
}

Veani deodorant is an effective antiperspirant that leaves your skin soft. But, when Veani deodorant gets old it sometimes loses its effectiveness.

In pretesting, these descriptions were judged to be evaluatively equivalant. Further, the descriptions were randomly assigned between-subjects to the Veani or Vode brand. 


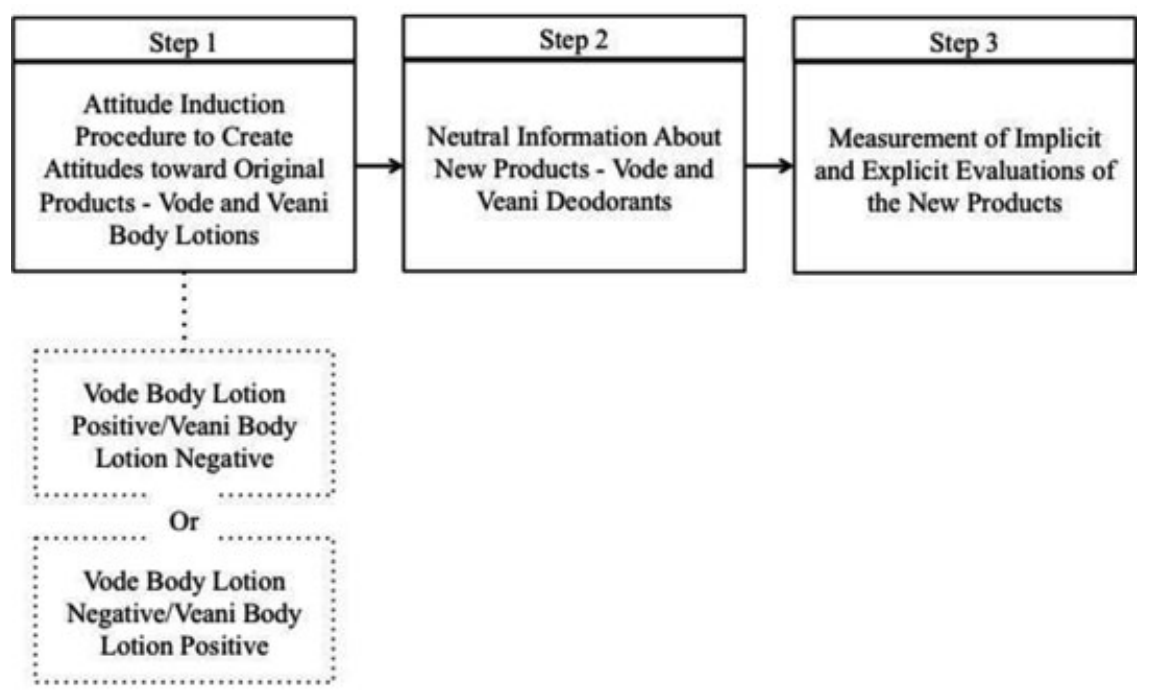

Figure 1. Overview of Study 1 procedure. Boxes with dotted lines represent between-subjects conditions.

Implicit Association Test (Greenwald et al., 1998). The IAT assesses associations among two concept categories (Vode Deodorant and Veani Deodorant) and two evaluative attributes (good and bad) by requiring that participants categorize stimulus items representing the four categories as quickly as possible using two keys of a computer keyboard. Participants used the "e" and "i" keys to classify items one at a time into the corresponding superordinate categories identified on the right or left side of the screen. Stimuli representing the concept categories included the names "Vode Deodorant" and "Veani Deodorant" as well as the pictures of the deodorants that were presented in the induction. Stimuli representing the evaluative attributes were good and bad words (e.g., rainbow, love, wonderful, vomit, death, awful).

The IATs consisted of seven trial blocks following the recommendation of Nosek, Greenwald, and Banaji (2005). Analysis with the $D$ algorithm (Greenwald, Nosek, \& Banaji, 2003) had the following features: response latencies $<400 \mathrm{~ms}$ were removed, and trial latencies were calculated from the beginning of the trial until the time of a correct response. A positive $D$ score indicates an implicit preference for Vode Deodorant over Veani Deodorant.

Self-Report Measures. Participants indicated their global evaluation of Vode and Veani deodorants on 7point scale ranging from Very Negative $(-3)$ to Very Positive (+3). Paralleling the relative format of the IAT, a difference score was calculated such that positive scores indicated an explicit preference for Vode Deodorant over Veani Deodorant.

\section{Procedure}

Participants were randomly assigned to view the Vode Body Lotion Positive or Vode Body Lotion Negative attitude induction. Following the induction, participants were told about the two new products (deodorant) produced by Vode and Veani. Participants then completed the IAT and self-report item measuring their attitudes toward the deodorants. The order of implicit and explicit measures was randomized across participants, and did not qualify any reported results.

\section{RESULTS}

\section{Attitude Transfer Occurred}

Recall that the information presented about Vode and Veani deodorant was evaluatively equal and was randomized between participants. This ensures that any difference in evaluations of Vode and Veani deodorants can only be attributed to participants' formed attitudes toward Vode and Veani body lotions (i.e., attitude transfer). As expected, participants in the Vode Body Lotion Positive condition showed a significantly more positive implicit evaluation of Vode Deodorant ( $M=0.18$, SD $=0.49$ ) than did participants in the Vode Body Lotion Negative condition $(M=-0.21, \mathrm{SD}=0.38), t(261)=$ $7.47, p<0.0001$, Cohen's $d=0.93$, indicating that attitude transfer occurred. Participants in the Vode Body Lotion Positive condition also reported a significantly more positive explicit evaluation of Vode Deodorant ( $M$ $=0.59, \mathrm{SD}=2.20)$ than did participants in the Vode Body Lotion Negative condition $(M=-0.18, \mathrm{SD}=2.23)$, $t(267)=2.82, p=0.01, d=0.17$. Notably, the explicit condition difference was much weaker than the implicit condition difference-perhaps indicating some explicit resistance to using the evaluations of one product to influence the other (Ranganath \& Nosek, 2008).

\section{Implicit Attitude Transfer Mediated Explicit Attitude Transfer}

In order to test for the mediating effect of implicit attitude formation on explicit attitude formation, the 
previous results were reproduced in a regression following the recommendations for mediation analysis by Baron and Kenny (1986). First, the valence of information presented about Vode and Veani Body Lotions significantly predicted participants' explicit attitude toward Vode and Veani Deodorants, $B=0.76$, SE = $0.27, \beta=0.17, p=0.01$. However, when implicit attitudes were added to the regression equation in a second step, the influence of condition on explicit attitude was smaller, $B=0.44$, $\mathrm{SE}=0.29, \beta=0.10, p=0.13$, and according to a Sobel analysis, significantly so, $Z=$ $3.28, p=0.001$. Importantly, the reverse was not true. As we showed previously, the valence of information presented about Vode and Veani Body Lotions significantly predicted participants' implicit attitude toward Vode and Veani Deodorants, $B=0.38, \mathrm{SE}=0.05, \beta$ $=0.42, p<0.0001$. However, the relationship between condition and implicit attitude remained after adding the explicit attitude to the regression equation in a second step, $B=0.36$, SE $=0.05, \beta=0.39, p<0.0001$.

\section{DISCUSSION}

Evaluations of one consumer product transferred to another product made by the same brand. Creating a preference for Vode over Veani body lotion led participants to develop a preference for Vode over Veani deodorant, even though participants had minimal, equivalent information about the two deodorants. These results are consistent with the research on brand extension that suggests that a company can use a generally favorable evaluation of the company in order to successfully launch new products on the market (Aaker \& Keller, 1990). We extend these findings by demonstrating attitude transfer in both implicit and explicit attitudes and, importantly, by showing that implicit attitude transfer mediated explicit attitude transfer, providing a mechanism through which brand extension effects may occur.

In Study 1, the information presented about the two new products was fairly neutral and evaluatively equivalent; as in most brand extension research, the new product is a "blank slate" onto which people project their pre-existing attitudes toward the original product. However, in a real-life context, a person is likely to get evaluative information about the new product too. The most theoretically (and practically) interesting conditions are when the information about the new product is evaluatively opposite that of the existing knowledge about the brand. Can positive information about a new brand product overcome pre-existing negative associations about another product on the brand? Can negative information about a new brand product be mitigated by pre-existing positive associations about another product on the brand? Study 2 tests whether implicit and explicit attitudes toward one product influence evaluations of a new product even when the information presented about the new product is opposite what is known about the original product.

\section{STUDY 2}

Participants read information about fictitious apple juices made by brands called Squeeze and Refresh that induced a clear preference for one brand over the other. In one condition, the Squeeze Apple Juice had positive features and Refresh Apple Juice had negative features; in the other condition, this was reversed. Next participants read brief introductions to two new products, orange juices, made by the same brands as the apple juices that participants had learned about previously. In one condition, the Squeeze Orange Juice had positive features and Refresh Orange Juice had negative features; in the other condition, this was reversed. We then measured participants' self-reported and implicit attitudes toward Squeeze and Refresh Orange Juices (the new products) using the same measures as in Study 1. See Figure 2 for an overview of the Study 2 procedure.

\section{METHOD}

\section{Participants}

Participants were volunteers at the Project Implicit research Web site (http://implicit.harvard.edu) who were randomly assigned to this study from the available pool of dozens of studies. Three hundred and ten people complete the study materials $\left(62 \%\right.$ women, $M_{\text {age }}=28$ years).

Attitude Induction Procedure. Participants read a vignette describing the results of a taste test comparing Squeeze Apple Juice and Refresh Apple Juice. In one condition, Squeeze Apple Juice was superior to Refresh Apple Juice; in the other condition, Squeeze Apple Juice was inferior to Refresh Apple Juice. The information about one juice was very positive and the information about the other juice was very negative in order to ensure a clear preference for one juice over the other.

Introduction to New Products. Participants were given information about two new products (Orange Juice) marketed on the same brand labels (Squeeze and Refresh) that produce the apple juice that they had learned about previously. Participants read another vignette describing the results of a different taste test comparing Squeeze Orange Juice and Refresh Orange Juice. In one condition, Squeeze Orange Juice was superior to Refresh Orange Juice; in the other condition, Squeeze Orange Juice was inferior to Refresh Orange Juice (see Appendix vignettes). The valence of the information presented about the new products (orange juices) was manipulated orthogonally to the manipulation of the valence of the information about the original products (apple juices). 


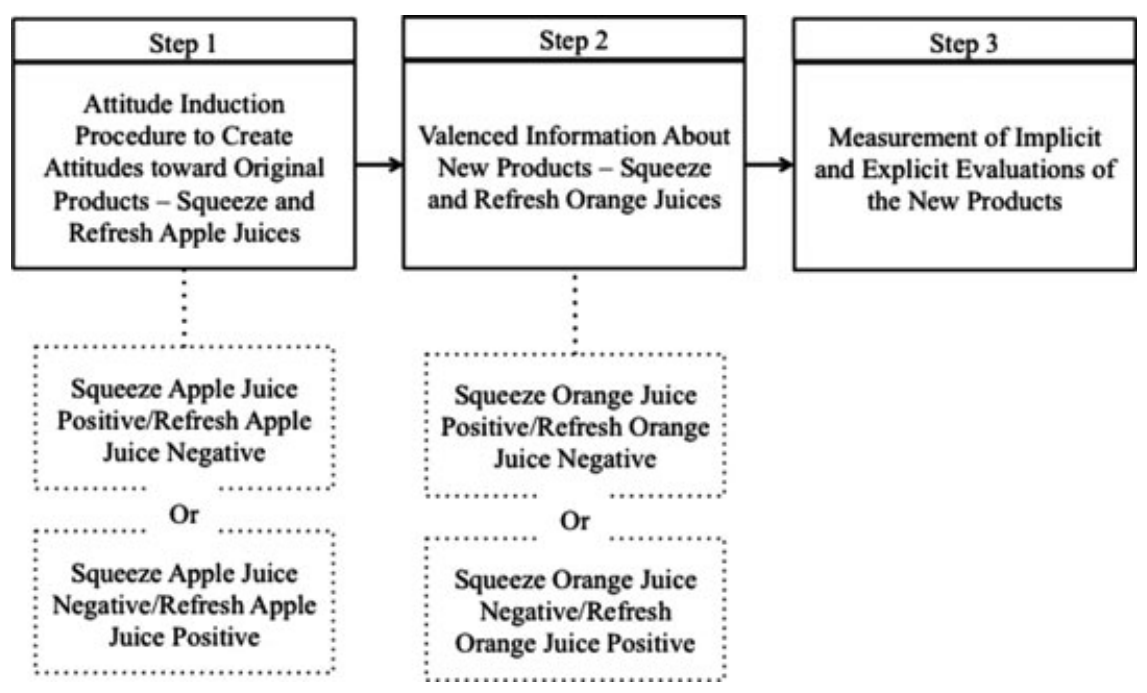

Figure 2. Overview of Study 2 procedure. Boxes with dotted lines represent between-subjects conditions.

Implicit Association Test. The IAT assessed associations among two concept categories (Squeeze Orange Juice and Refresh Orange Juice) and two evaluative attributes (good and bad). Stimuli representing the concept categories included the names "Squeeze Orange Juice" and "Refresh Orange Juice" printed on pictures of orange juice cartons. Stimuli representing the evaluative attributes included positive and negative words (e.g., rainbow, love, wonderful, vomit, death, awful). The procedural details of the IAT were identical to those of Study 1. A positive $D$ score indicates an implicit preference for Squeeze Orange Juice over Refresh Orange Juice.

Self-Report Measures. Participants indicated their global evaluation of Squeeze Orange Juice and Refresh Orange Juice on 7-point scale ranging from Very Negative $(-3)$ to Very Positive (+3). As in Study 1, a difference score was created such that a positive score indicates an explicit preference for Squeeze Orange Juice over Refresh Orange Juice.

\section{RESULTS AND DISCUSSION}

Two 2 (apple juice condition: Squeeze Positive vs. Squeeze Negative) $\times 2$ (orange juice condition: Squeeze Positive vs. Squeeze Negative) ANOVAs were used to test the influence of participants' attitude toward Squeeze Apple Juice on their attitudes toward Squeeze Orange Juice separately for implicit and explicit attitudes (Figure 3).

\section{Implicit (But Not Explicit) Attitude Transfer Occurred}

Explicit attitude transfer occurs if the information presented about the apple juices influences self-reported evaluations of the orange juices. This did not occur. Participants did not have significantly more positive attitudes toward Squeeze Orange Juice (compared to Refresh Orange Juice) when Squeeze Apple Juice was described as being positive $(M=0.78$, $\mathrm{SD}=4.10)$ compared to when Squeeze Apple Juice was described as being negative $(M=-0.27$, $\mathrm{SD}=$ $4.22), F(1,305)=2.71, p=0.10, \eta^{2}=0.01$. However, as one would expect, the valence of the information presented about the orange juices did affect evaluations of the orange juices. Squeeze Orange Juice was rated much more favorably than Refresh Orange Juice when it had positive features $(M=3.01, \mathrm{SD}=$ 3.11) compared to when it had negative features $(M$ $=-2.68, \mathrm{SD}=3.02), F(1,305)=54.37, p<0.0001$, $\eta^{2}=0.45$. Also, there was no interaction between apple juice condition and orange juice condition, $F$ $(1,305)=0.11, p=0.74, \eta^{2}<0.001$, indicating that the initial information about Squeeze Apple Juice did not have a differential impact on explicit attitudes toward Squeeze Orange Juice based on valence or congruence with the orange juice information. These results suggest that participants explicitly resisted attitude generalization; they did not use the information presented about Squeeze Apple Juice when making a judgment about Squeeze Orange Juice. The fact that Study 1 showed explicit generalization but Study 2 did not is easy to understand by noting that in Study 2, participants had real information about the new products, whereas in Study 1, they had virtually no useful information about the new products. In other words, when participants had useful information about the new products, they used it, and explicitly ignored the information about the original products.

Although participants explicitly ignored the information about apple juice for their orange juice evaluations, they were not able to ignore it implicitly. Participants had significantly more positive implicit attitudes toward Squeeze Orange Juice (compared to Refresh 


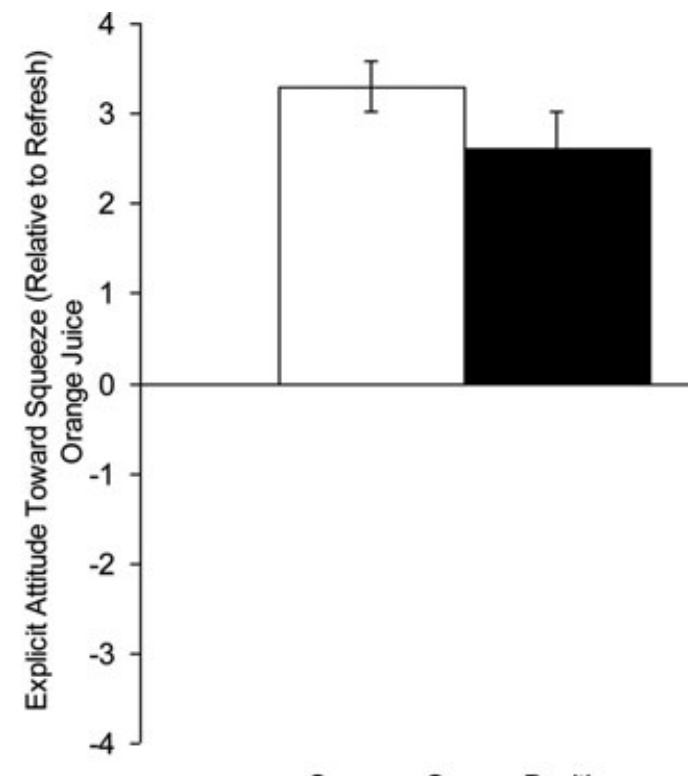

Squeeze Orange Positive $\square$ Squeeze Apple Positive

- Squeeze Apple Negative

\section{Implicit Attitudes}

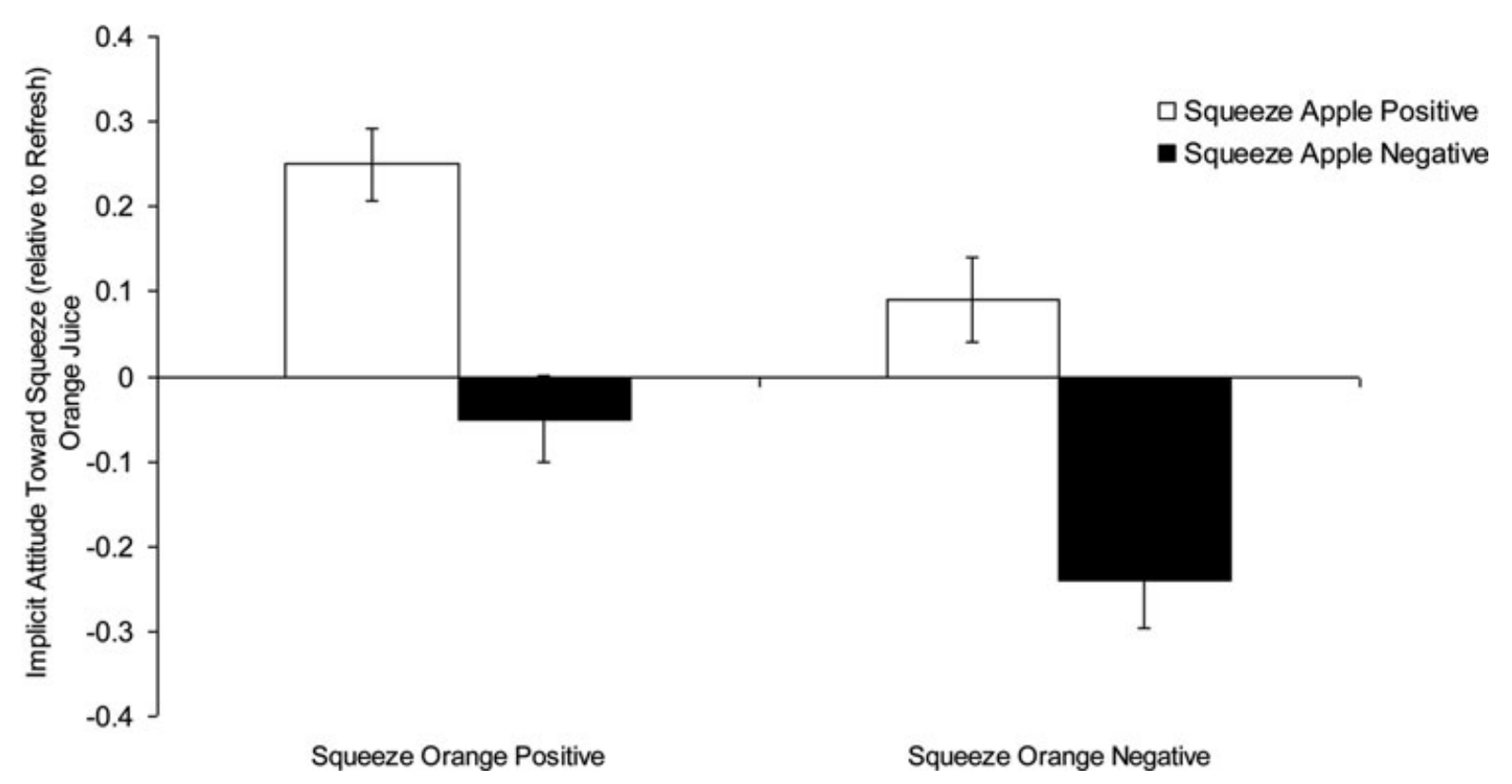

Figure 3. Study 2 implicit and explicit attitudes as a function of the information presented about the orange juices (the product that participants learned about initially), and the information presented about the apple juices made by the same brands. A higher score indicates a stronger preference (IAT- $D$ or self-reported evaluation) for Squeeze Orange Juice relative to Refresh Orange Juice.

Orange Juice) when Squeeze Apple Juice was described as being positive $(M=0.18, \mathrm{SD}=0.39)$ compared to when Squeeze Apple Juice was described as being negative $(M=-0.15, \mathrm{SD}=0.46), F(1,296)=40.78, p<$ $0.0001, \eta^{2}=0.12$. There was also an effect of the valence of the information presented about the orange juices themselves. Squeeze Orange Juice was implicitly evaluated more favorably when it was described as being positive $(M=0.12, \mathrm{SD}=0.41)$ compared to when it was described as being negative $(M=-0.08$, SD $=0.48)$, $F(1,296)=12.85, p<0.0001, \eta^{2}=0.04$. Finally, there was no interaction between apple juice condition and 
orange juice condition, $F(1,296)=0.04, p=0.84, \eta^{2}<$ 0.001 . These results suggest that participants were unable to resist implicit attitude transfer; the information presented about Squeeze Apple Juice influenced the way in which they implicitly evaluated Squeeze Orange Juice even though they had direct information about the qualities of the Orange Juice. In particular, those participants that first heard that Squeeze Apple Juice was better than Refresh Apple Juice, but then heard that Refresh Orange Juice was better than Squeeze Orange Juice nonetheless showed a slight implicit preference for the Squeeze Orange Juice over Refresh Orange Juice $(M=0.09, \mathrm{SD}=0.42, d=0.21)$ reflecting the prior experience with the apple juices. The same occurred in the reverse case. Participants that heard Squeeze Apple Juice described as worse than Refresh Apple Juice, but then heard that Squeeze Orange Juice was better than Refresh Orange Juice nonsignificantly preferred Refresh Orange Juice implicitly $(M=-0.05$, $\mathrm{SD}=0.41, d=0.12$ ). Note that the information about the new products was influential in attitude formation, it just was not sufficient to eliminate the influence of the information about the original products.

\section{GENERAL DISCUSSION}

The present research explored the role of attitude transfer in the formation of implicit and explicit attitudes toward consumer products. Study 1 showed the transfer effect within the consumer behavior realm, demonstrating that implicit and explicit attitudes toward one product rub off on another product made by the same brand. Further, implicit attitude transfer mediated the effect of product information on explicit attitude transfer, suggesting that the effect occurs automatically. Study 2 extended the results of Study 1 by showing that implicit evaluations of a new product are influenced by implicit evaluations of another product of the same brand, even when the information presented about the new product is opposite in valence to the information presented about the original product.

The results of these studies demonstrate that people can explicitly take into account the information presented about a new product, but finding out that a new product is quite good does not lead to unambiguously favorable implicit evaluations if they already have a negative implicit evaluation of a related product. This is consistent with the idea that people may have associations in their minds that they would judge to be false if given the opportunity to consciously evaluate them (Gawronski \& Bodenhausen, 2006) and with research showing that implicit attitudes change more slowly than explicit attitudes (Gregg et al., 2006; Rydell et al., 2006; Wilson et al., 2000).

Implicit evaluations of consumer brands are important for two reasons. First, they have been shown to be important in predicting buying behavior. Maison et al. (2004) demonstrated that implicit brand evalua- tions provide additional predictive power above explicit brand evaluations alone. Additionally, implicit evaluations are better than explicit evaluations at predicting buying behaviors when a consumer is under cognitive load (Friese, Wanke, \& Plessner, 2006; Gibson, 2008).

Implicit evaluations of consumer brands are also important to the extent that they influence explicit evaluations. Ranganath and Nosek (2008) found that, even when participants explicitly resisted using their attitude toward one person in evaluating a new person from the same group, the associative relationship resulted in explicit attitude transfer after a several day delay (see also Smith et al., 2012). The same may occur with brands. Over time, implicit attitude formation may carry weight in determining ultimate explicit judgments once people forget the details of the original learning episode.

An interesting direction for future research would be to manipulate the similarity between products made by the same parent brand. Brand extension has been shown to be effective only to the extent that there is a "fit" between the two product classes (i.e., the two products are of a similar kind; Aaker \& Keller, 1990). This suggests that explicit transfer should increase as a function of the perception of similarity; however, brand associations between completely unrelated products might still lead to the transfer of implicit attitudes because they may be more sensitive to the shared brand label than the similarity of product features.

These findings illustrate the importance of attending to two forms of brand evaluation. On the one hand, people can reason explicitly about individual products and their features in order to decide which they prefer. On the other hand, people can be influenced implicitly by simple associations — such as a brand label—that make it easier for new products to inherit the evaluations of existing products on the same label regardless of the product features and quality.

\section{REFERENCES}

Aaker, D. A., \& Keller, K. L. (1990). Consumer evaluations of brand extensions. Journal o Marketing, 54, 27-40.

Allport, G. W. (1935). Attitudes. In C. Murchison (Ed.), A handbook of social psychology (pp. 788-844). Worcester, MA: Clark University Press.

Baron, R. M., \& Kenny, D. A. (1986). The moderator-mediator variable distinction in social psychological research: Conceptual, strategic and statistical considerations. Journal of Personality and Social Psychology, 51, 1173-1182.

Brunel, F. F., Tietje, B. C., \& Greenwald, A. G. (2004). Is the Implicit Association Test a valid and valuable measure of implicit consumer social cognition? Journal of Consumer Psychology, 14, 385-404.

Cacioppo, J. T., Marshall-Goodell, B. S., Tassinary, M. L., \& Petty, R. E. (1992). Rudimentary determinants of attitudes: Classical conditioning is more effective when prior knowledge about the attitude stimulus is low than high. Journal of Experimental Social Psychology, 208, 207-233. 
De Houwer, J. (2009). The propositional approach to associative learning as an alternative for association formation models. Learning \& Behavior, 37, 1-20.

Eagley, A., \& Chaiken, S. (1993). The psychology of attitudes. Fort Worth, TX: Harcourt Brace Jovanovich.

Fazio, R. H. (1986). How do attitude guide behavior? In R. M. Sorrentino \& T. Higgins (Eds.), Handbook of motivation and cognition (pp. 204-243). New York: Guilford Press.

Friese, M., Wänke, M., \& Plessner, H. (2006). Implicit consumer preferences and their influence on product choice. Psychology \& Marking, 23, 727-740.

Gawronski, B., \& Bodenhausen, G. V. (2006). Associative and propositional processes in evaluation: An integrative review of implicit and explicit attitude change. Psychological Bulletin, 132, 692-731.

Gibson, B. (2008). Can evaluative conditioning change evaluations of mature brands? New evidence from the Implicit Association Test. Journal of Consumer Research, 35, 178188.

Gilbert, D. T. (1991). How mental systems believe. American Psychologist, 46, 107-119.

Greenwald, A. G., McGhee, D. E., \& Schwartz, J. L. K. (1998). Measuring individual differences in implicit cognition: The Implicit Association Test. Journal of Personality and Social Psychology, 74, 1464-1480.

Greenwald, A. G., \& Banaji, M. R. (1995). Implicit social cognition: Attitudes, self-esteem, and stereotypes. Psychological Review, 102, 4-27.

Greenwald, A. G., Nosek, B. A., \& Banaji, M. R. (2003). Understanding and using the Implicit Association Test: I. An improved scoring algorithm. Journal of Personality and Social Psychology, 85, 197-216.

Greenwald, A. G., Poehlman, T. A., Uhlmann, E. L., \& Banaji, M. R. (2009). Understanding and using the Implicit Association Test: III. Meta-analysis of predictive validity. Journal of Personality and Social Psychology, 97, 1741.

Gregg, A. P., Seibt, B., \& Banaji, M. A. (2006). Easier done than undone: Asymmetry in the malleability of automatic preferences. Journal of Personality and Social Psychology, 90, 1-20.

Kapoor, H., \& Heslop, L. A. (2009). Brand positivity and competitive effects on the evaluation of brand extensions. International Journal of Research in Marketing, 26, 228-237.

Karpinski, A., Steinman, R. B., \& Hilton, J. L. (2005). Attitude importance as a moderator of the relationship between implicit and explicit attitude measures. Personality and Social Psychology Bulletin, 31, 949-962.

Maison, D., Greenwald, A. G., \& Bruin, R. H. (2004). Predictive validity of the Implicit Association Test in studies of brands, consumer attitudes, and behavior. Journal of Consumer Psychology, 14, 405-415.

Morein, M. (1975). Shift from brand to product line marking. Harvard Business Review, 53, 56-64.

Nosek, B. A. (2005). Moderators of the relationship between implicit and explicit evaluation. Journal of Experimental Psychology: General, 134, 565-584.

Nosek, B. A., Greenwald, A. G., \& Banaji, M. R. (2005). Understanding and using the Implicit Association Test: II. Method variables and construct validity. Personality and Social Psychology Bulletin, 31, 166-180.

Nosek, B. A., \& Smyth, F. L. (2007). A multitrait-multimethod validation of the Implicit Association Test: Implicit and explicit attitudes are related but distinct constructs. Experimental Psychology, 54, 14-29.
Nosek, B. A., Smyth, F. L., Hansen, J. J., Devos, T., Lindner, N. M., Ranganath, K. A., et al. (2007). Pervasiveness and correlates of implicit attitudes and stereotypes. European Review of Social Psychology, 18, 36-88.

Olson, M. A., \& Fazio, R. H. (2002). Implicit acquisition and manifestation of classically conditioned attitudes. Social Cognition, 20, 89-103.

Ranganath, K. A., \& Nosek, B. A. (2008). Implicit Attitude generalization occurs immediately; explicit attitude generalization takes time. Psychological Science, 19, 249-254.

Ranganath, K. A., Smith, C. T., \& Nosek, B. A. (2008). Distinguishing automatic and controlled components of attitudes from direct and indirect measurement methods. Journal of Experimental Social Psychology, 44, 386-396.

Ratliff, K. A., \& Nosek, B. A. (2010). Creating distinct implicit and explicit attitudes with an illusory correlation paradigm. Journal of Experimental Social Psychology, 46, $721-728$

Ratliff, K. A., \& Nosek, B. A. (2011). Negativity and outgroup biases in attitude formation and transfer. Personality and Social Psychology Bulletin, 37, 1692-1703.

Rydell, R. J., McConnell, A. R., Mackie, D. M., \& Strain, L. M. (2006). Of two minds: Forming and changing valenceinconsistent implicit and explicit attitudes. Psychological Science, 17, 954-958.

Rydell, R. J., McConnell, A. R., Strain, L. M., Claypool, H. M., \& Hugenberg, K. (2007). Implicit and explicit attitudes respond differently to increasing amounts of counterattitudinal information. European Journal of Social Psychology, $37,867-878$.

Shanks, D. R. (1995). The psychology of associative learning. London, England: Cambridge University Press.

Sloman, S. A. (1996). The empirical case for two systems of reasoning. Psychological Bulletin, 119, 3-22.

Smith, E. R, \& DeCoster, J. (2000). Dual-process models in social and cognitive psychology: Conceptual integration and links to underlying memory systems. Personality \& Social Psychology Review, 4, 108-131.

Smith, C. T., Ratliff, K. A., \& Nosek, B. A. (2012). Rapid assimilation: Automatically integrating new information with existing beliefs. Social Cognition, 30, 199-219.

Strack, F. (1992). The different routes to social judgments: Experiential versus informational strategies. In L. L. Martin $\&$ A. Tesser (Eds.), The construction of social judgments (pp. 249-275). Hillsdale, NJ: Erlbaum.

Strack, F., \& Deutsch, R. (2004). Reflective and impulsive determinants of social behavior. Personality and Social Psychology Review, 8, 220-247.

Thurstone, L. L. (1931). The measurement of social attitudes. Journal of Abnormal and Social Psychology, 26, 249-269.

Walther, E., Nagengest, B., \& Traselli, C. (2005). Evaluative conditioning in social psychology: Some facts and speculations. Cognition and Emotion, 19, 175-196.

Wilson, T. D., Lindsey, S., \& Schooler, T. Y. (2000). A model of dual attitudes. Psychological Review, 107, 101-126.

The data in this paper were collected as part of the second and third authors' Bachelor's Theses at Tilburg University. Thanks to Nicole Mead and Colin Tucker Smith for their helpful comments. This research was supported by Project Implicit.

Correspondence regarding this article should be sent to: Kate A. Ratliff, Warandelaan 2, Box 90153, 5000LE Tilburg, The Netherlands. Tel: +31 624941550 (k.a.ratliff@uvt.nl). 


\section{APPENDIX A: ATTITUDE INDUCTION MATERIALS USED IN STUDY 1.}

Vode Body Lotion Positive/Veani Body Lotion Negative

Condition (all sentences presented randomly)

Vode body lotion as a very nice smell

Vode body lotion will leave your skin soft

Vode body lotion gives your skin a nice glow

Vode vody lotion is not sticky or greasy

Vode body lotion will not stain your clothes

Vode body lotion makes your skin look younger

Vode body lotion is a great value

Veani body lotion has an unpleasant smell

Veani body lotion can irritate your skin

Veani body lotion is thin and sticky

Veani body lotion makes your skin look greasy

Veani body lotion does not make your skin look younger

Veani body lotion can stain your clothes

Veani body lotion is quite expensive

Vode Body Lotion Negative/Veani Body Lotion Positive

Condition (all sentences presented randomly)

Veani body lotion as a very nice smell

Veani body lotion will leave your skin soft

Veani body lotion gives your skin a nice glow

Veani vody lotion is not sticky or greasy

Veani body lotion will not stain your clothes

Veani body lotion makes your skin look younger

Veani body lotion is a great value

Vode body lotion has an unpleasant smell

Vode body lotion can irritate your skin

Vode body lotion is thin and sticky

Vode body lotion makes your skin look greasy

Vode body lotion does not make your skin look younger

Vode body lotion can stain your clothes

Vode body lotion is quite expensive

\section{APPENDIX B: ATTITUDE INDUCTION MATERIALS USED IN STUDY 2.}

\section{Original Product (Apple Juices)}

Imagine that there are two new brands of apple juice on the market. One is named "Squeeze" and the other is named "Refresh." A consumer magazine did a taste test where people were able to taste both brands of apple juice. People were very positive about Refresh Apple Juice. They found it to be delicious and fresh-tasting. They said that it was like drinking freshly pressed juice. Many said that Refresh made the best apple juice they would ever had. People were very negative about Squeeze Apple Juice. They found it to be disgusting and spoiled-tasting. They said that it did not even taste like apples. Many said that Squeeze made the worst apple juice they would ever had. Take a moment to think about your impression of Refresh and Squeeze before continuing.

\section{New Product (Orange Juices)}

Imagine that "Squeeze" and "Refresh" also each made a brand of orange juice. The same consumer magazine did another taste test where people were able to taste both brands of orange juice. People were very positive about Refresh Orange Juice. They found it to be delicious and fresh-tasting. They said that it was like drinking freshly pressed juice. Many said that Refresh made the best orange juice they would ever had. People were very negative about Squeeze Orange Juice. They found it to be disgusting and spoiled-tasting. They said that it did not even taste like oranges. Many said that Squeeze made the worst orange juice they would ever had. Take a moment to think about your impression of Refresh and Squeeze before continuing. 